\title{
Introducing Pathogen Reduction Technology in Poland: A Cost-Utility Analysis
}

\author{
Maria Agapova ${ }^{a}$ \\ Elzbieta Lachert ${ }^{\mathrm{b}}$ \\ Ewa Brojer ${ }^{b}$ \\ Magdalena Letowska ${ }^{b}$ \\ Brian Custer ${ }^{\mathrm{c}, \mathrm{d}}$ \\ a Pharmaceutical Outcomes Research and Policy Program, University of Washington, Seattle, WA, USA; \\ ${ }^{\mathrm{b}}$ Institute of Haematology and Transfusion Medicine, Warsaw, Poland; \\ ${ }^{\mathrm{c}}$ Blood Systems Research Institute, San Francisco, CA, USA; \\ d Laboratory Medicine, University of California, San Francisco, San Francisco, CA, USA
}

Piotr Grabarczyk ${ }^{b}$

\section{Keywords}

Pathogen reduction technology · Mirasol PRT . Poland . Blood safety · Cost-effectiveness · ICER

\section{Summary}

Background: Mirasol ${ }^{\circledR}$ pathogen reduction technology (PRT) uses UV light and riboflavin to chemically inactivate pathogens and white blood cells in blood components. In the EU, Mirasol PRT is CE-marked for both plasma and platelet treatment. In Poland, the decision to introduce PRT treatment of the national supply of fresh frozen plasma has spurred interest in evaluating the cost-effectiveness of this strategy. Methods: A decisionanalytic model evaluated the incremental costs and benefits of introducing PRT to the existing blood safety protocols in Poland. Results: Addition of PRT treatment of plasma to current screening in Poland is estimated to cost 2.595 million PLN per quality-adjusted life year (QALY) $(610,000$ EUR/QALY); treating both plasma and platelet components in addition to current safety interventions had a lower cost of 1.480 million PLN/QALY (348,000 EUR/QALY). Conclusions: The results suggest that in Poland the cost per QALY of PRT is high albeit lower than found in previous economic analyses of PRT and nucleic acid testing in North America. Treating both platelets and plasma components is more cost-effective than treating plasma alone. Wide confidence intervals indicate high uncertainty; to improve the precision of the health economic evaluation of PRT, additional hemovigilance data are needed.

\section{Introduction}

Mirasol $^{\circledR}$ pathogen reduction technology (PRT) uses UV light and riboflavin to inactivate pathogens and white blood cells (leukocytes) in blood components. The technology is CE-marked for the reduction of pathogens and inactivation of residual white blood cells in donor platelet concentrates or plasma for transfusion, and is intended to provide broad-spectrum safety benefits beyond existing blood safety screening strategies.

Countries like the USA and Canada have complex screening and testing algorithms. However, as the number of safety measures increases the incremental effectiveness of each additional safety measure diminishes. In those countries that have yet to adopt every available safety procedure, the potential of PRT is greater. Poland is transitioning to also have a multi-layer safety protocol with the recent decision to adopt nucleic acid amplification testing (NAT) and PRT of plasma products. The aim of this economic evaluation was to estimate the cost-utility of plasma PRT as an addition to blood safety interventions and quarantine used in Poland, and to compare the additional benefits that might be achieved by adding platelets PRT to the use of plasma PRT.

In June of 2010, the Polish Ministry of Health began implementation of nationwide plasma PRT (P-PRT) treatment of its fresh frozen plasma supply [1]. The cost-effectiveness of this technology has been previously assessed for the treatment of plasma and platelets in Canada [2]. Although the population of each country is different, the quantity of blood collected to supply patient needs is comparable between the two countries. Canada's two major blood collectors, Hema-Quebec and Canadian Blood Services, shipped approximately 1,500,000 labile components in 2008-2009 [3, 4]. Similarly, approximately $1,000,000$ donations are processed into $1,600,000-1,800,000$ blood components per year in Poland [5]. De- 
Table 1. Estimated residual risks of adverse events in current screening scenario and PRT reduction potential

\begin{tabular}{|c|c|c|c|c|}
\hline $\begin{array}{l}\text { Pathogen or adverse } \\
\text { event }\end{array}$ & $\begin{array}{l}\text { Current residual or } \\
\text { assumed risk as } \\
1 / \text { thousands (low and } \\
\text { high deterministic } \\
\text { range) }\end{array}$ & Source & $\begin{array}{l}\text { PRT fold } \\
\text { reduction, (low and } \\
\text { high deterministic } \\
\text { range) }\end{array}$ & $\begin{array}{l}\text { Post-PRT reference } \\
\text { residual risk as } \\
1 \text { /thousands }\end{array}$ \\
\hline Bacteria (platelets) & $\begin{array}{l}1 / 5 \\
(1 / 50,1 / 3)\end{array}$ & Ramirez-Arcos et al. [12], Schrezenmeier et al. [10] & $50,(10,90)$ & $1 / 250$ \\
\hline $\begin{array}{l}\text { Bacteria (other } \\
\text { components) }\end{array}$ & $\begin{array}{l}1 / 47 \\
(1 / 100,1 / 33)\end{array}$ & International Forum: Haemovigilance [28] & $50,(10,90)$ & $1 / 2,350$ \\
\hline HIV & $\begin{array}{l}1 / 1,408 \\
(1 / 14,085,1 / 141)\end{array}$ & data collected for Roth et al. [29] & $10,(5,15)$ & $1 / 14,000$ \\
\hline $\mathrm{HCV}$ & $\begin{array}{l}1 / 93 \\
(1 / 925,1 / 9)\end{array}$ & data collected for Roth et al. [29] & $10,(5,15)$ & $1 / 930$ \\
\hline $\mathrm{HBV}$ & $\begin{array}{l}1 / 200 \\
(1 / 2,004,1 / 20)\end{array}$ & data collected for Roth et al. [29] & $10,(5,15)$ & $1 / 2,000$ \\
\hline Syphilis & $\begin{array}{l}1 / 270 \\
(1 / 2,500,1 / 25)\end{array}$ & $\begin{array}{l}\text { Institute of Hematology and Transfusion Medicine, } \\
\text { Warsaw. Poland. Data is based on the National Health } \\
\text { Fund Bulletin [7] }\end{array}$ & $10,(5,15)$ & $1 / 2,700$ \\
\hline CMV & $\begin{array}{l}1 / 80 \\
(1 / 167,1 / 53)\end{array}$ & Blajchman et al. [30] & $2,(1.25,2.75)$ & $1 / 160$ \\
\hline FNHTR & $\begin{array}{l}1 / 30 \\
(1 / 61,1 / 20)\end{array}$ & Brojer et al. [8] & $2,(1.01,2.99)$ & $1 / 60$ \\
\hline TA-GVHD & $\begin{array}{l}1 / 2,400 \\
(1 / 4,762,1 / 1,587)\end{array}$ & $\begin{array}{l}\text { Serious Hazards of Transfusion - Annual Report } \\
\text { Summary [31] }\end{array}$ & $2,(1.25,2.75)$ & $1 / 4,800$ \\
\hline TRIM & $\begin{array}{l}1 / 150 \\
(1 / 333,1 / 100)\end{array}$ & Custer et al. [2] & $1.5,(1.01,1.99)$ & $1 / 225$ \\
\hline HTLV & $\begin{array}{l}1 / 4,300 \\
(1 / 8,621,1 / 2,865)\end{array}$ & Custer et al. [2] & $10,(5,15)$ & $1 / 43,000$ \\
\hline WNV & $\begin{array}{l}1 / 500 \\
(1 / 5,000,1 / 50)\end{array}$ & assumption & $10,(5,15)$ & $1 / 5,000$ \\
\hline
\end{tabular}

spite these similarities, as a result of more testing and screening of donated blood in Canada, such as West Nile Virus (WNV) NAT and bacterial culture, the health burden of transfusion-related adverse events is thought to be smaller in Canada. In counterbalance, healthcare costs are typically lower in Poland, often by $50 \%$ or more [6]. Thus, the cost-effectiveness of PRT in Poland merits additional investigation.

\section{Material and Methods}

\section{Overview}

A previously developed decision-analytic model, which assessed the costutility of Mirasol PRT in Canada, was modified to reflect the blood safety profile of Poland and PRT strategies of interest to its healthcare decision makers [2]. This model was designed to simulate the costs and effectiveness of blood safety interventions and to provide results in terms of incremental costs, effects in quality-adjusted life years (QALYs), and incremental cost-effectiveness ratios (ICERs) by comparing the costs and effects of new strategies - treating plasma only (P-PRT) or plasma and platelet components (PP-PRT) with PRT - on current blood safety procedures/screening.

There were several modifications to the existing model: i) the types and levels of risk within the model were modified (table 1); infectious diseases not known to be prevalent in Poland such as Chikungunya virus and Trypanosoma cruzi were excluded. ii) In light of the decision by the Poland Ministry of Health to adopt pathogen reduction of plasma components as part of its $\mathrm{Na}$ tional Blood Center program, the model included the strategy, PRT treatment of plasma only (P-PRT). iii) Costs of testing and of medical interventions to treat adverse events were modified and updated to reflect Polish costs in 2013 PLN. iv) To account for the country-wide introduction of this technology fixed costs of investing in PRT technology were added to this model. v) Previous initial post-transfusion and annual survival probabilities for the overall distribution of patients were reduced by $10 \%$ to adjust for a potential difference in healthcare quality and health outcomes. This analysis reflects a year 2014 Polish healthcare system perspective. Discount rates for costs and effects were set at $3 \%$. We used TreeAge decision analytic software (TreeAge Pro, Williamstown, MA, USA) to create the model and perform analyses. Cost-effectiveness results are reported as PLN/QALY, and in order to provide perspective in a more widely used currency, also in EUR/QALY (assuming a 4.25 PLN $=1.00$ EUR conversion rate).

\section{Risks of Adverse Events}

Poland blood centers test all donations by serological and NAT methods for HIV, HBV, and HCV. Serologic methods are used to detect syphilis. HTLV and WNV screening are not used, and less than $10 \%$ of the blood supply is gammairradiated [7]. CMV-safe components are not widely available; although a portion of the supply is leukoreduced, specific modeling of leukoreduction was not included in the analysis [8]. No estimates of WNV seroprevalence were available for Poland. Due to previous reports of outbreaks in Italy, Greece and Eastern Europe and because Canada screens for WNV, whereas Poland does not, we 
Table 2. Treatment costs for adverse events

\begin{tabular}{|c|c|c|}
\hline Adverse event & Description of treatment & Cost, $\mathrm{PLN}^{\varsigma}$ \\
\hline \multirow[t]{2}{*}{$\mathrm{HIV}^{*}$} & cost of care, monitoring, and HAART per year & 7,351 \\
\hline & cost of treating symptomatic infection per month (episode) & 5,145 \\
\hline \multirow[t]{3}{*}{$\mathrm{HBV}^{*}$} & cost of treating initial HBV infection & 3,553 \\
\hline & annual cost of treating chronic infection & 6,005 \\
\hline & cost of decompensated cirrhosis or hepatocellular carcinoma & 4,288 \\
\hline \multirow[t]{3}{*}{$\mathrm{HCV}^{*}$} & cost of treating HCV infection - first year & 3,553 \\
\hline & cost of treating chronic HCV infection & 3,553 \\
\hline & cost of decompensated cirrhosis or hepatocellular carcinoma & 4,288 \\
\hline \multirow[t]{3}{*}{$\mathrm{HTLV}^{\dagger}$} & annual cost of treating HTLV symptomatic infection & 919 \\
\hline & cost of T-cell leukemia & 33,691 \\
\hline & cost of outpatient treatment & 13,255 \\
\hline $\mathrm{WNV}^{\dagger}$ & cost of inpatient treatment for symptomatic WNV & 42,645 \\
\hline \multirow[t]{4}{*}{ Sepsis ${ }^{\dagger / *}$} & cost of treating acute sepsis ${ }^{\dagger}$ & 8,882 \\
\hline & annual cost of future care following sepsis or patients with sequelae (decreases & 4,832 \\
\hline & each year $)^{*}$ & 2,858 \\
\hline & & 2,839 \\
\hline \multirow[t]{2}{*}{ TA-GVHD $^{\dagger}$} & cost of acute TA-GVHD treatment & 22,653 \\
\hline & cost of chronic TA-GVHD per year & 3,675 \\
\hline FNHTR $^{\dagger}$ & cost of treatment and monitoring FNHTR & 184 \\
\hline $\mathrm{CMV}^{\dagger}$ & cost of CMV treatment and care & 2,817 \\
\hline \multirow[t]{2}{*}{ Syphilis ${ }^{\dagger}$} & cost of treatment including physician time & 342 \\
\hline & cost of symptomatic untreated syphilis per year & 3,735 \\
\hline \multicolumn{3}{|c|}{$\begin{array}{l}\text { TA-GVHD = Transfusion-associated graft-versus-host disease; FNHTR = febrile non-hemolytic transfusion reaction; } \\
\text { TRIM = transfusion-associated immunomodulation. } \\
{ }^{\star} \text { Estimated or assumed based on Canadian information but adjusted to reflect the costs of healthcare utilization in Poland. } \\
\text { †Institute of Hematology and Transfusion Medicine, Warsaw. Poland. Data is based on the National Health Fund Bulletin [7]. } \\
{ }^{\S} \text { Estimates were varied } \pm 25 \% \text { in one-way sensitivity analysis. }\end{array}$} \\
\hline
\end{tabular}

increased the residual risk of WNV from 1/1,000,000 (Canada analysis) to $1 / 500,000$ [9]. If no testing or information regarding the probability of adverse event occurrence for Poland was available (e.g. CMV, transfusion-associated graft-versus-host disease, transfusion-related immunomodulation, and HTLV), we used the residual risk data from the previous PRT analysis [2].

This model was designed to account for component-specific differential risks and mortality. Blood recipients in the cohort are assigned to red cells only transfusion (69\% of recipients), any platelet-containing transfusion $(6 \%)$, or any non-platelet plasma-containing transfusion (25\%). The probability belonging to each of these groups was derived from the mix of components released for clinical use in 2009 at one hospital in Poland. In the platelet arm of the model, patients are further stratified by the type of platelet preparation received. In Poland, platelet components are prepared using buffy coat (66\%) or apheresis $(34 \%)$ techniques [5]. We assumed buffy coat preparations using pooled platelets are derived from independent donors, resulting in four exposures for risks, with one exception: the risk of bacterial contamination in buffy coat and apheresis platelet preparation was assumed to be the same [10]. No information was available on transfusions which include a mix of platelets, red cells, and plasma. Based on the previously modeled Canadian estimates, we assumed that recipient risks with the use of PRT were halved for the proportion (39\%) of recipients receiving a mixture of PRT-treated plasma and/or platelets and untreated red cell components.

As bacteria culture screening is not performed in Poland, rates of transfusion-transmitted bacterial infections are expected to be higher than in settings with culture protocols in place [11]. The residual risk of bacterial contamination in plasma components was raised from the Canadian estimate of 1/50,000 to $1 / 47,000$. We modeled the bacterial risk in platelet products at $1 / 5,000$ [13] based on the assumption that the risk is between the culture yield estimates found in Germany $(1 / 2,500)[10]$ and that found in Canada $(1 / 10,000)[12]$. We assumed that approximately $15 \%$ of transmitted cases experienced clinically apparent adverse events. Post-transfusion mortality attributable to sepsis was modeled independent of adverse events as component-specific additional probability of death post-transfusion. In red cells, plasma and platelet products these probabilities are $7 \%, 12 \%$ and $22 \%$, respectively. Risk of death for several adverse events was also raised by $50 \%$ in the population with compromised immune systems ( $25 \%$ of recipient cohort).

The potential of PRT to reduce the residual risk of each event, previously defined as the PRT pathogen-specific risk reduction factors, were not altered from the Canadian analysis. In addition, we did not expect any changes in the natural progression of disease between the two populations. Therefore, the post-transfusion Markov disease progression models (probabilities and outcomes) were not modified.

\section{Costs}

The per donation aggregate cost of current screening strategies, 52 PLN was calculated as the function of a single cost of serological determination of HIV, HBV, HCV, and syphilis (12 PLN/donation) plus the cost of individual (ID) and minipool multiplex NAT for presence of HIV, HBV, and HCV as well as the cost of gamma-irradiation and CMV screening [8]. We estimated that approximately half of the blood supply is screened using MP NAT (27 PLN/donation) and half is screened using ID NAT (37 PLN/donation). Gamma-irradiation and CMV testing are not universally performed. We estimated that less 
Table 3. Costs, effects and incremental cost-utility of competing strategies for PRT in Poland

\begin{tabular}{|c|c|c|c|c|}
\hline & Current screens & $\begin{array}{l}\text { Versus P-PRT } \\
\text { (reference case) }\end{array}$ & Versus PP-PRT & P-PRT versus PP-PRT \\
\hline Total costs, PLN & 53.69 & 90.15 & 113.63 & \\
\hline Total effects, QALY & 7.5970195 & 7.5970339 & 7.5970610 & \\
\hline Incremental costs, PLN & & 36.46 & 59.94 & 23.48 \\
\hline Incremental effectiveness, QALY & & $0.0000143(7.5)$ & $0.0000414(21.7)$ & $0.0000271(14.2)$ \\
\hline 95\% CI approximation* & & $1,801,000-3,672,000$ & $1,032,000-2,121,000$ & $621,000-1,238,000$ \\
\hline ICER, EUR/QALY* & & 610,000 & 348,000 & 208,000 \\
\hline ICER, PPP\$/QALY* & & $1,380,000$ & 787,000 & 470,000 \\
\hline
\end{tabular}

than $10 \%$ of donations undergo these safety measures. The per-donation cost of gamma-irradiation (62 PLN/donation) and CMV testing (26 PLN/donation) when distributed across all donations amounted to 8.80 PLN.

The cost of PRT was also revised for Poland in two ways. First, based on proprietary price data provided by TerumoBCT for this project, costs by component type were included: 349 PLN for PP-PRT and 127 PLN for P-PRT. Second, since this technology is new to Poland, we added the overhead cost of new equipment to the model. The additional fixed costs attributable to new equipment, spread across all donations, were 1.62 PLN for P-PRT and 1.93 PLN for PP-PRT. Costs of healthcare utilization were provided by Drs. Elżbieta Lachert and Dr. Ryszasrd Poglod (personal commication, Institute of Haematology and Transfusion Medicine (IHTM), Warsaw, Poland, September 2010) (table 2). Cost inputs were rounded to nearest PLN.

\section{Sensitivity Analyses}

In light of the many simplifications and assumptions in this analysis, we performed extensive one-way sensitivity analyses. Point estimates were varied either using known ranges of plausible values or fixed values 25\% lower and higher and then ranked in order of decreasing influence in a series of one-way analyses to produce tornado diagrams. The true probability of a bacterial infection from contaminated products is largely unknown in Poland. We modeled the probabilities of bacterial contamination and death from sepsis separately and investigated the influence of varying their joint probability on the ICER of P-PRT versus current screens in a two-way sensitivity analysis. We also performed probabilistic sensitivity analyses. Distributions used in probabilistic sensitivity analyses have been previously described (technical appendix in the previous publication) [2]. In the current analysis, costs of all serological (mean \pm SD: $12, \pm 6$ PLN) and NAT screens (ID NAT mean $37 \pm 18$ PLN; MP NAT mean $27 \pm 13$ PLN) were approximated to gamma-distributions [14]. Expected values (means) and 95\% confidence interval (95\% CI) approximations (2.5 and 97.5 percentiles) were calculated from the cost and effect distributions of a 10,000 iteration Monte Carlo simulation.

In a worst-case scenario analysis, we assumed that every donation was screened by individual NAT. Thus, our estimates of residual risk of viral infectious agents in blood components are overestimated. Using an updated window period transmission risk model developed by Weusten et al. [15], we estimated that in Poland the residual risks of HCV, HBV and HIV would decrease to roughly $1 / 6,232,000$ (67-fold reduction), 1/358,000 (1.8-fold reduction) and $1 / 1,971,000$ (1.4-fold reduction), respectively based on a Poland-specific analysis of available data (personal communication R. Bruhn). This data was collected as part of a 21-country effort (Poland included) to establish a dataset of first-time, lapsed, and repeat donation HIV, HCV, and HBV seroprevalence [16].

\section{Results}

Estimates of costs and effects of current interventions as compared to adding P-PRT or PP-PRT to the currents screening procedures in Poland are reported in table 3. Based on the data available and assumptions used in this analysis, life expectancy of the average transfused patient in Poland is just under 8 QALYs. To this number, treatment of plasma with PRT on average adds an additional 7.5 quality-adjusted life-minutes at the additional cost of 36.46 PLN; treatment of plasma and platelets increases the benefit by 21.7 quality-adjusted life-minutes at the additional cost of 59.94 PLN. Across an annual estimate of 500,000 blood recipients the QALYs gained are 7.2 for P-PRT and 20.7 for PP-PRT. P-PRT is less cost-effective at 2.595 million PLN/QALY (610,000 EUR/ QALY) than treating both plasma and platelet components at 1.480 million PLN/QALY (348,000 EUR/QALY). Comparing the two PRT strategies head-to-head and treating P-PRT as the current strategy, PP-PRT cost-utility is 883,000 PLN/QALY (208,000 EUR/ QALY). ICER results are also provided in table 3 in USD adjusted for purchasing power parities [17].

\section{Sensitivity Analysis}

\section{Deterministic Sensitivity Analyses}

To assess the impact of individual model variable uncertainty on the results, one-way sensitivity analysis of every variable in the model was performed to identify which variables across their specified ranges had the greatest influence on the cost-utility of the reference case, P-PRT. The top ten most influential variables of the reference case strategy were selected and presented in hierarchical order using a Tornado diagram (fig. 1a). Probabilities related to two adverse events are important in the reference case; those related to bacteria and HCV rank 1st and 2nd, respectively. Two additional bacteria-related variables appear in the Tornado diagram: quality of life weight for sepsis (on a scale of $0-1$, with 0 representing death and 1 representing perfect health) ranks 4 th and the probability of death from sepsis ranks 9th. 
Fig. 1. Tornado diagrams ranking the top most influential variables by providing the ICER ranges associated with each variables' estimated upper and lower bounds. a provides the most influential variables in the comparison of P-PRT to current screens and $\mathbf{b}$ provides the most influential variables in the comparison of PP-PRT to P-PRT.

The legend for each plot provides the description of the variable, followed by the point estimate and the range used in one-way sensitivity analysis in brackets. The variable value producing the lower ICER result (left edge of each horizontal bar) is written first and the higher ICER is presented second. QoL = Quality of life.

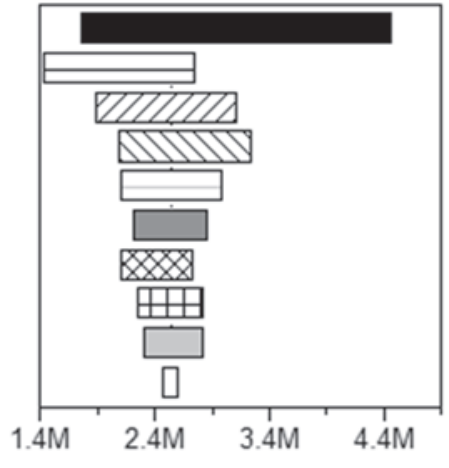

Probability of bacterial contamination in plasma: $1 / 50,000[1 / 33,000$ to $1 / 100,000]$ Probability of HCV contamination of donation: $1 / 92,500$ [1/9,250 to $1 / 925,000]$ $\square$ Unit cost of plasma PRT: 127 PLN [95 to 159]

$\triangle$ QoL weight for long term consequences of sepsis: 0.69 [0.59 to 0.79 ]

$\square$ Discount rate for effects: 0.03 [0.01 to 0.05 ]

$\square$ Component use adjustment factor for PRT: 1.1 [1.0 to 1.2]

Mortality probability in the year of the transfusion: 0.25 [0.1 to 0.3$]$

$\boxplus$ Annual underlying mortality probability varied $-25 \%$ and $+25 \%$

$\square$ Probability of death due to bacteremia/sepsis: 0.066 [0.033 to 0.099$]$

$\square$ QoL weight for average person requiring transfusion: 0.90 [0.81 to 0.99$]$

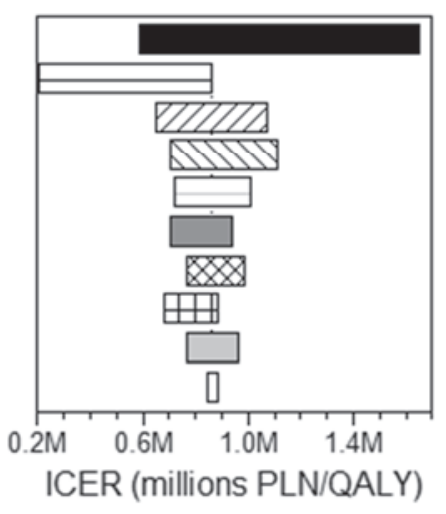

Probability of bacterial contamination in platelets: $1 / 5,000[3 / 10,000$ to $1 / 10,000]$

$\square$ Donor bacterial exposures per platelet preparation: 1 [1 to 6]

$\square$ Cost of PRT per platelet donation: 349 PLN [262 to 436]

$\triangle$ QoL weight for long term consequences of sepsis: 0.69 [0.59 to 0.79$]$

$\square$ Discount rate for effects: 0.03 [0.01 to 0.05 ]

$\square$ Mortality probability in the year of the transfusion: 0.25 [0.1 to 0.3$]$

$\otimes$ Probability of death due to bacteremia/sepsis: 0.066 [0.033 to 0.099$]$

$\boxplus$ Probability of HCV contamination of donation: $1 / 92,500$ [1/9,250 to $1 / 925,000]$

$\square$ Annual underlying mortality probability varied $-25 \%$ and $+25 \%$

$\square$ QoL weight for average person requiring transfusion: 0.90 [0.81 to 0.99 ]

Table 4. ICERs ofP-PRT versus current screening methods varying probabilities of bacterial contamination of plasma products and death attributable to sepsis

\begin{tabular}{lrrr}
\hline $\begin{array}{l}\text { Probability of bacterially contaminated } \\
\text { plasma product }\end{array}$ & \multicolumn{3}{l}{ Probability of death attributable to sepsis } \\
\cline { 2 - 4 } & $1 / 1,000$ & $1 / 100$ & \multicolumn{1}{c}{$1 / 10$} \\
\hline $1 / 500,000$ & $12,478,000$ & $9,359,000$ & $9,359,000$ \\
$1 / 45,000$ & $3,116,000$ & $2,876,000$ & $2,199,000$ \\
$1 / 5,000$ & 381,000 & 366,000 & 264,000 \\
\hline
\end{tabular}

The third most influential parameter in the P-PRT model is the cost of the technology. The ICER varied between 2.1 and 3.4 million PLN/QALY as cost of P-PRT (127 PLN) was varied $\pm 25 \%$. Discount rate for effects ranks 5 th. Component use ranks 6 th and demonstrates that the potential loss of efficaciousness of each blood component, when varied from 0 to $20 \%$, impacts the ICER result. Mortality in the first year of transfusion, when varied from 0.1 to 0.3 , ranks 7 th [18]. Annual mortality ranks 8 th when varied $25 \%$, and quality of life post-transfusion ranks 10 th, when varied from 0.81 to 0.99 on a $0-1$ scale.

The tornado diagram of the current screens and PP-PRT comparison indicates that probability of bacterial contamination continues to be very influential (fig. 1b). Related to bacterial contamination is the number of donor exposures per platelet preparation. As in the model evaluating plasma only PRT, the cost of PP-PRT ranks 3rd in influence. The ranking of remaining influential factors were similar between the PP-PRT and P-PRT versus current screening analyses.
To investigate the scope of influence that bacterial contamination of platelets has on ICER results, a univariate sensitivity analysis for the residual risk of bacterial contamination was performed (fig. 2). We found the ICER for PP-PRT was very sensitive to a decreasing risk of bacterial contamination. At an approximate residual risk of $1 / 15,000$ per platelet preparation, the ICER of PP-PRT (vs. current screening methods) increases to converge with the ICER of P-PRT (vs. current screening methods at 2.6 million PLN/ QALY). The ICER for PP-PRT reaches 6 million PLN/QALY (1.5 million EUR/QALY) as the residual risk of bacterial contamination in platelets diminishes to levels estimated for bacterial contamination of plasma $(1 / 50,000)$. Further examination of bacterial contamination of plasma products revealed far more model sensitivity to bacterial contamination of plasma than to the probability of death from sepsis (table 4). For instance, very different P-PRT versus current screening methods ICERs may result from the same joint probability of $1 / 5,000,000$ of death from sepsis, given a contaminated plasma product: 9,359,000.00 PLN, if the probability of 
Fig. 2. One-way sensitivity analysis of the effect of residual risk of bacterial contamination in platelets on the ICER results. As the baseline risk of bacterial risk increases from $1 / 50,000$ (to the residual risk level modeled in plasma) to $1 / 3,333$, the ICER of strategies including PRT treatment of platelets decreases dramatically when comparing PP-PRT to current screens (grey dashed line):from roughly 6.5 million PLN/QALY to 0.6 million PLN/QALY; and slightly when PPPRT is compared to P-PRT (dark grey solid line): from 3.4 million PLN/QALY to 1.2 million PLN/QALY.
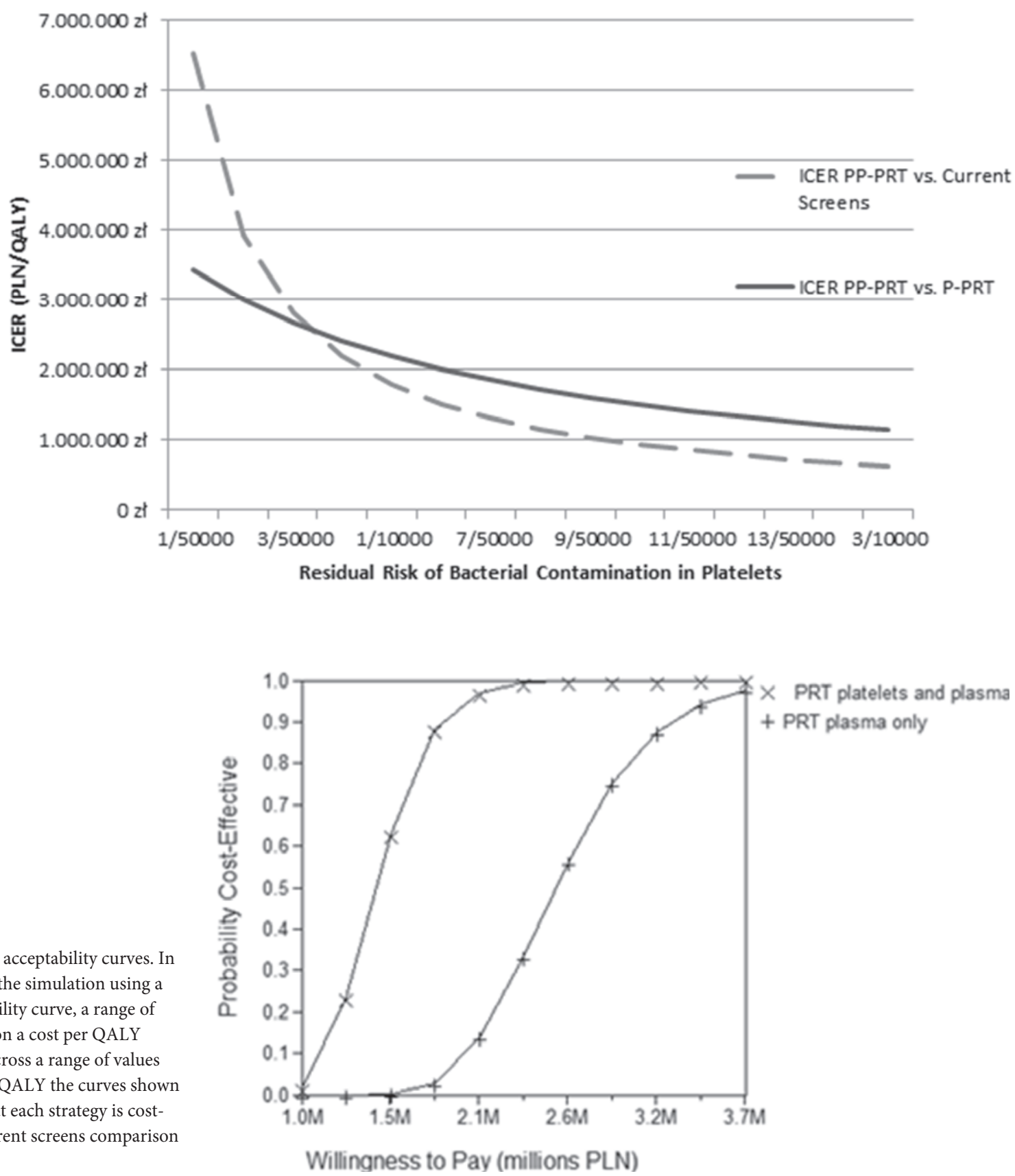

Fig. 3. Cost-effectiveness acceptability curves. In order to plot the results of the simulation using a cost-effectiveness acceptability curve, a range of willingness to pay values (on a cost per QALY basis) has to be defined. Across a range of values from 1.0-3.7 million PLN/QALY the curves shown indicate the probability that each strategy is costeffective relative to the current screens comparison strategy.

show that the probability of PP-PRT being cost-effective compared to P-PRT is higher at any given willingness to pay threshold.

high, or 381,000 PLN, if the situation is reversed. Results from the worst-case scenario indicated that very low residual risks of $\mathrm{HCV}$, HBV, and HIV increases the ICER values by $10 \%$ and by $5 \%$, when comparing P-PRT and PP-PRT, respectively, to current screening methods.

\section{Probabilistic Sensitivity Analyses}

This overall uncertainty can be expressed in a manner that is easier to interpret with cost-effectiveness acceptability curves. Across a range of willingness to pay 1.0-3.7 million PLN/QALY, the curves indicate the probability that each strategy is cost-effective relative to the comparison strategy (fig. 3). The results

\section{Discussion}

The aim of this economic evaluation was to estimate the costutility of P-PRT as an addition to blood safety interventions used in Poland, and to compare the additional benefit that might be achieved by adding platelet PRT to the use of P-PRT. P-PRT alone was less cost-effective (2.6 million PLN/QALY, 610,000 EUR/ QALY) than treating both plasma and platelet components (1.5 
million PLN/QALY, 348,000 EUR/QALY). Sensitivity analysis indicated that factors related to risk of bacterial contamination, HCV residual risk, and the cost of PRT on a per unit treated basis are the most influential model parameters. Adjusting for currencies, but not for differences in purchasing power, PRT treatment of components in Poland is approximately $70 \%$ more cost-effective than in Canada.

While yield data from serological and NAT testing is often available, few countries have residual risk information, and the actual risk of adverse events (accounting for transmissibility) is largely unknown. Thus, our economic evaluation is limited by the insufficiently understood residual risks of adverse events in Poland. This issue is most keenly relevant in the case of bacterial contamination, but is also applicable to all other infectious and noninfectious threats included in the model, with perhaps the exceptions of HIV, HCV, and HBV. Because transmissibility or transmission potential does not explicitly play a role in calculating the probabilities of an adverse event in this model, we may have overestimated bacterial risk as empirical evidence supports the expectation that few bacterially contaminated platelet and even fewer plasma components cause overt symptoms, sepsis, or lead to death $[10,13]$. However, when adapting this model from the Canadian to the Polish setting we increased, only slightly, the residual risk of bacterial contamination of plasma components. We also appropriately increased residual risk of platelet bacterial contamination to account for large differences in safety measures between the two countries. The reporting of high rates of detection of bacterial contamination in all three labile components in similar settings, as described by studies performed in Germany and Croatia [19-21], does not reconcile easily with very low rates of adverse events in hemovigilance data [22]. By varying, simultaneously, the probability of contamination in plasma products and death due to sepsis, we showed that a specific joint probability of death from sepsis may lead to disparate ICERs in our model.

Another important limitation is the assumption of one unit of a component per one blood recipient. We may have underestimated the baseline residual risks to recipients. We did account for the fact that recipients are likely to be receiving a mix of PRT-treated and untreated (red cell) components. Since proportions of different components transfused to blood recipients during a transfusion episode in Poland are not reported, we assumed the data from Canada could be applied to Poland. Further, initial and annual post-transfusion mortality remain important considerations in measuring cost-effectiveness of transfusion safety interventions. This analysis relied on a composite of post-transfusion survival and general population life expectancy tables from three different settings: Poland, Canada, and SCANDAT (Denmark and Sweden). In an attempt to adjust for quality of healthcare differences among Denmark, Sweden, Canada and Poland, annual mortality was increased by $10 \%$ from the expected values used in the Canadian analysis. The increase in incremental cost per QALY in response to this change illustrates that underlying life expectancy of post-transfusion is influential in the level of cost-effectiveness an intervention in blood safety can achieve.
With the exception of possibly overestimating the incidence of adverse events, such as sepsis and hepatitis $C$, this analysis represents a conservative approach to evaluating the health-economic benefits of PRT for six reasons: i) We modeled the incremental safety benefit of PRT atop, not in place of, existing safety measures in use in Poland, the majority of risk having been mitigated by existing screening strategies. This may be interpreted as underutilizing the protective potential of PRT. ii) In addition, we did not model the potential of PRT to reduce the possibility of adverse events to zero as has been done in previous analyses $[23,24]$. While other reports have demonstrated $1.5-6 \mathrm{log} / \mathrm{ml}$ reductions in the presence of infectious agents using Mirasol [26], we have modeled roughly 1-2 log reductions. iii) From an economic point of view, safety interventions in the population of transfusion patients have less potential to accumulate benefits over a lifespan because life expectancy is shorter as a result of the underlying condition for which the blood transfusion is required and because transfusion recipients are generally older members of the population. iv) We may have underestimated the costs and consequences of adverse events in Poland, limiting the potential cost-savings associated with PRT. v) The number of exposures attributed to buffy coat-prepared platelet components remains uncertain. Although up to four donations contribute to one buffy coat preparation in Poland, we chose to model only one exposure rather than four [10]. In one-way sensitivity analysis, we show that the number of exposures is an influential variable and increasing the number of exposures improves cost-effectiveness of PP-PRT. vi) In the worst-case scenario, in which all donations undergo individual NAT HIV, HCV, and HBV screening leading to far lower residual risks, we showed only small increases in the ICER.

This analysis represents a rare exploration into the economic profile of blood safety interventions across multiple country profiles. We are not aware of any existing economic evaluations of blood safety interventions in Poland. Having previously adopted NAT of donated blood without the benefit of health economic analyses to guide decision making, Poland has joined the USA [26], Canada [2], Sweden [27], and most other developed nations in showing a willingness to pay high costs for blood safety. The results of the Polish analysis indicate that PP-PRT is more cost-effective than P-PRT. However, hemovigilance data and additional evaluation of blood safety interventions are needed in Poland to improve the precision of the assessment of the health economic potential of PRT.

\section{Acknowledgments}

$\mathrm{BC}$ and MA designed the study and wrote the manuscript. EL, EB, MC, and PG provided data and BC, EL, EB, MC, and PG critically reviewed the manuscript. MA performed the analyses.

\section{Disclosure Statement}

This work was partially funded by an unrestricted grant from TerumoBCT, Inc. The authors have no other conflicts of interest or financial disclosures with respect to the content of this manuscript. 


\section{References}

1 Poland's Ministry of Health Selects CaridianBCT Mirasol System for Blood Supply Safety. Medical Devices Business Review. 2009. http://invitrodiagnostics.medicaldevices-business-review.com/news/polands_ministry_of_ health selects caridianbct mirasol system for blood supply_safety_100624 (last accessed March 31, 2015).

2 Custer B, Agapova M, Martinez RH: The cost-effectiveness of pathogen reduction technology as assessed using a multiple risk reduction model. Transfusion 2010;50:2461-2473.

3 Héma-Québec Annual Report 2013-2014. 2014. www. hema-quebec.qc.ca/userfiles/file/RA_2013-2014/HQ_ RA_2013-2014_ANG_FINAL(1).pdf (last accessed March 31, 2015).

4 Canadian Blood Services Annual Report. A Report for Canadians 2012/2013. 2013. http://video.bloodservices. ca/Annual2013/index.html (last accessed March 31, 2015).

5 Antoniewicz-Papis J, Letowska M: The Polish Blood Transfusion Service - quality, guidelines, laws, selected topics of interest and future challenges. Transfus Med Hemother 2006;33:401-406.

6 WHO: CHOosing Interventions That Are Cost Effective (WHO-CHOICE) 2007. www.who.int/choice/ country/pol/cost/en/index.html (last accessed March 31, 2015).

7 Rosiek A, Tomaszewska A, Lachert E, AntoniewiczPapis J, Poglod R, Letowska M: Blood Transfusion Service in Poland in 2011. J Transfus Med 2012;5:159170.

8 Brojer E: Annual Report from the Regional Blood Center. Warsaw, Poland, 2009.

9 European Center for Disease Control: West Nile Virus Transmission in Europe. Solna, European Center for Disease Control, 2010. www.ecdc.europa.eu/en (last accessed March 31, 2015)

10 Schrezenmeier H, Walther-Wenke G, Muller TH, Weinauer F, Younis A, Holland-Letz T, Geis G, Asmus J, Bauerfeind U, Burkhart J, Deitenbeck R, Forstemann E, Gebauer W, Hochsmann B, Karakassopoulos A, Liebscher UM, Sanger W, Schmidt M, Schunter F, Sireis W, Seifried E: Bacterial contamination of platelet concentrates: results of a prospective multicenter study comparing pooled whole blood-derived platelets and apheresis platelets. Transfusion 2007;47:644-652.

11 Letowska M: Medical Standards for Collection, Preparation and Distribution of Blood and Blood Components for Public Blood Establishments; Collective Work, 2nd ed. Warsaw, Institute of Hematology and Transfusion Medicine, 2011

12 Ramirez-Arcos S, Jenkins C, Dion J, Bernier F, Delage $\mathrm{G}$, Goldman M: Canadian experience with detection of bacterial contamination in apheresis platelets. Transfusion 2007;47:421-429.
Brecher ME, Hay SN: Bacterial contamination of blood components. Clin Microbiol Rev 2005;18:195-204.

14 Briggs A, Claxton, Karl, Sculpher M: Decision Modelling for Health Economic Evaluation (Handbooks for Health Economics Evaluation). Oxford, Oxford University Press, 2006.

15 Weusten J, Vermeulen M, van Drimmelen H, Lelie N: Refinement of a viral transmission risk model for blood donations in seroconversion window phase screened by nucleic acid testing in different pool sizes and repeat test algorithms. Transfusion 2011;51:203215.

16 Bruhn R, Lelie N, Custer B, Busch M, Kleinman S: Prevalence of human immunodeficiency virus RNA and antibody in first-time, lapsed, and repeat blood donations across five international regions and relative efficacy of alternative screening scenarios. Transfusion 2013;53(suppl 3):2399-2412.

17 OECD (2010), OECD.Stat, (database). http://stats.oecd. org/index.aspx?DataSetCode $=$ PPPGDP (last accessed March 31, 2015).

18 Kamper-Jorgensen M, Ahlgren M, Rostgaard K, Melbye M, Edgren G, Nyren O, Reilly M, Norda R, Titlestad K, Tynell E, Hjalgrim H: Survival after blood transfusion. Transfusion 2008;48:2577-2584.

19 Pietersz RN, Reesink HW, Panzer S, Oknaian S, Kuperman S, Gabriel C, Rapaille A, Lambermont M, Deneys V, Sondag D, Ramírez-Arcos S, Goldman M, Delage G, Bernier F, Germain M, Vuk T, Georgsen J, Morel P, Naegelen C, Bardiaux L, Cazenave JP, Dreier J, Vollmer T, Knabbe C, Seifried E, Hourfar K, Lin CK, Spreafico M, Raffaele L, Berzuini A, Prati D, Satake M, de Korte D, van der Meer PF, Kerkhoffs JL, Blanco L, Kjeldsen-Kragh J, Svard-Nilsson AM, McDonald CP, Symonds I, Moule R, Brailsford S, Yomtovian R, Jacobs MR: Bacterial contamination in platelet concentrates. Vox Sang 2014;106:256-283.

20 Walther-Wenke G, Wirsing von Konig CH, Däubener W, Heiden M, Hoch J, Hornei B, Volkers P; Working Party on Bacteria Safety in Transfusion Medicine, Advisory Board of the German Ministry of Health, Berlin: Monitoring bacterial contamination of blood components in Germany: effect of contamination reduction measures. Vox Sang 2011;100:359-366.

21 Vuk T, Barisic M, Hecimovic A, Rukavina L, Batarilo I, Šarlija D, Jukić I: Bacterial contamination of blood products at the Croatian Institute of Transfusion Medicine: results of eleven-year monitoring. Transfus Med 2012;22:432-439.

22 Funk MB, Lohmann A, Guenay S, Henseler O, Heiden M, Hanschmann KM, Keller-Stanislawski B: Transfusion-transmitted bacterial infections - haemovigilance data of German blood establishments (1997-2010). Transfus Med Hemother 2011;38:266-271.
3 Janssen MP, van der Poel CL, Buskens E, Bonneux L, Bonsel GJ, van Hout BA: Costs and benefits of bacterial culturing and pathogen reduction in the Netherlands. Transfusion 2006;46:956-965.

24 Postma MJ, van Hulst M, De Wolf JT, Botteman M, Staginnus U: Cost-effectiveness of pathogen inactivation for platelet transfusions in the Netherlands. Transfus Med 2005; 15:379-387.

25 Marschner S, Goodrich R: Pathogen reduction technology treatment of platelets, plasma and whole blood using riboflavin and UV light. Transfus Med Hemother 2011;38:8-18.

26 Jackson BR, Busch MP, Stramer SL, AuBuchon JP: The cost-effectiveness of NAT for HIV, HCV, and HBV in whole-blood donations. Transfusion 2003;43:721-729.

27 Davidson T, Ekermo B, Gaines H, Lesko B, Akerlind B: The cost-effectiveness of introducing nucleic acid testing to test for hepatitis $\mathrm{B}$, hepatitis $\mathrm{C}$, and human immunodeficiency virus among blood donors in Sweden. Transfusion 2011;51:421-429.

28 International Forum: Haemovigilance. Vox Sang 2006; 90:207-241.

9 Roth WK, Busch MP, Schuller A, Ismay S, Cheng A, Seed CR, Jungbauer C, Minsk PM, Sondag-Thull D, Wendel S, Levi JE, Fearon M, Delage G, Xie Y, Jukic I, Turek P, Ullum H, Tefanova V, Tilk M, Reimal R, Castren J, Naukkarinen M, Assal A, Jork C, Hourfar MK, Michel P, Offergeld R, Pichl L, Schmidt M, Schottstedt V, Seifried E, Wagner F, Weber-Schehl M, Politis C, Lin CK, Tsoi WC, O'Riordan J, Gottreich A, Shinar E, Yahalom V, Velati C, Satake M, Sanad N, Sisene I, Bon AH, Koppelmann M, Flanagan P, Flesland O, Brojer E, Letowska M, Nascimento F, Zhiburt E, Chua SS, Teo D, Stezinar SL, Vermeulen M, Reddy R, Park Q, Castro E, Eiras A, Gonzales Fraile I, Torres P, Ekermo B, Niederhauser C, Chen H, Oota S, Brant LJ, Eglin R, Jarvis L, Mohabir L, Brodsky J, Foster G, Jennings C, Notari E, Stramer S, Kessler D, Hillyer C, Kamel H, Katz L, Taylor C, Panzer S, Reesink HW: International survey on NAT testing of blood donations: expanding implementation and yield from 1999 to 2009. Vox Sang 2012;102:82-90.

30 Blajchman MA, Goldman M, Freedman JJ, Sher GD: Proceedings of a consensus conference: prevention of post-transfusion CMV in the era of universal leukoreduction. Transfus Med Rev 2001;15:1-20.

31 Serious Hazards of Transfusion: Annual Report Summary 2007. Manchester, SHOT, 2008. 